\title{
Influência de Fatores Estruturais no Processo de Gelificação de Pectinas de Alto Grau de Metoxilação
}

\author{
Edimir M. Brandão e Cristina T. Andrade
}

Resumo: Duas amostras de pectina de alto grau de metoxilação, amostras A e B, foram purificadas, levando-se em conta os teores em grupos metoxílicos. Sua caracterização estrutural foi realizada através de dosagem de açúcares neutros com auxílio de cromatografia gasosa, GLC, e determinação do grau de metoxilação por técnicas de cromatografia líquida de alta resolução, HPLC. A amostra A apresentou teores mais elevados em açúcares neutros totais e grau de metoxilação mais alto. As viscosidades intrínsecas, $[\eta]=3,68 \mathrm{dL} / \mathrm{g}$ e $[\eta]=3,56 \mathrm{dL} / \mathrm{g}$ foram determinadas a $\mathrm{pH} 7,0$ para as amostras A e B, respectivamente. A pH 3,0, valores menores foram obtidos. A gelificação das amostras foi investigada, em função da concentração e da temperatura, medindo-se os módulos de armazenamento, G', e de perda, G”, em função do tempo. A pH 3,0 a pectina A apresentou taxas de gelificação mais elevadas, tanto em função da concentração como da temperatura.

Palavras-chave: Pectina, grau de metoxilação, gelificação

\section{Introdução}

As pectinas, polissacarídeos estruturais, formam um grupo complexo de polissacarídeos que são encontrados na parede celular primária e nas camadas intercelulares de plantas terrestres. Elas estão associadas à celulose, hemicelulose e lignina ${ }^{[1-3]} \mathrm{e}$ são mais abundantes em frutos e em tecidos jovens, tais como cascas de frutas cítricas $(30 \%)$, dentre as quais o limão é a fonte mais abundante ${ }^{[1,4]}$.

As pectinas contribuem para a adesão entre as células e para a resistência mecânica da parede celular $^{[1-3]}$. Além de seu papel importante no crescimento das células ${ }^{[5]}$, elas estão envolvidas em interações com agentes patogênicos, e a sua quan- tidade e natureza são determinantes para a textura de frutos e vegetais em geral, durante o seu crescimento, amadurecimento, armazenamento e processamento $^{[6]}$.

Estruturalmente, as moléculas de pectina são constituídas de uma cadeia principal linear de unidades repetidas de $(1 \rightarrow 4)$ - $\alpha$-D-ácido galacturônico, sendo que parte destas unidades apresenta-se esterificada, como éster metílico (Figura 1). As cadeias de resíduos galacturonato são, porém, interrompidas por unidades de $(1 \rightarrow 2)-\alpha$-L-ramnose, às quais estão ligadas cadeias laterais, formadas por açúcares neutros. Essas cadeias laterais são responsáveis pela união das moléculas de pectina à matriz polissacarídica da parede celular vegetal ${ }^{[2,7,8]}$. 


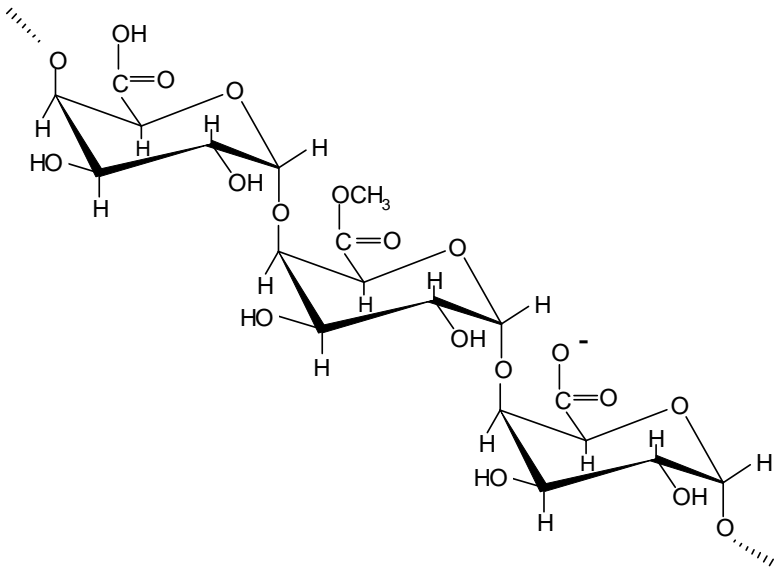

Figura 1. Estrutura química da cadeia de pectina ${ }^{[29]}$.

Embora o ácido D-galacturônico seja o principal açúcar constituinte das substâncias pécticas em geral, proporções variáveis de outros açúcares, tais como D-galactose, L-arabinose, D-xilose, L-ramnose, L-fucose e traços de 2-O-metilfucose também podem ser encontrados ${ }^{[8-10]}$.

Genericamente, as pectinas são subdivididas em duas classes, uma com alto grau de metoxilação $(>50 \%)$, HMP, e a outra com baixo grau de metoxilação $(<50 \%)$, LMP, que pode também possuir grupos amida. Comercialmente, as pectinas com alto grau de metoxilação apresentam teores na faixa 55 a $75 \%$, já nas de baixo grau de metoxilação, esses teores variam na faixa 15 a $45 \%$. Quando amidadas, as pectinas de baixo teor em grupamentos metoxílicos apresentam composição em grupamentos amida ${ }^{[11]}$ na faixa 10 a $25 \%$.

As HMP possuem considerável poder gelificante e são amplamente usadas na gelificação de sucos de frutas para a obtenção de geléias ${ }^{[1]}$. A presença de cadeias laterais, principalmente com unidades de arabinose e galactose ${ }^{[8,12]}$, afeta significativamente as propriedades funcionais das pectinas, tais como solubilidade, gelificação, formação de filme e propriedades reológicas, além de favorecer a agregação em soluções concentradas ${ }^{[8]}$.

Pectinas com alto grau de metoxilação gelificam em meio ácido, em presença de altas concentrações de um co-soluto, geralmente sacarose. Este processo de gelificação é complexo, havendo, ainda, divergência sobre seu mecanismo ${ }^{[7,13,14]}$.

As pectinas são polissacarídeos muito utilizados industrialmente, principalmente em produtos alimentícios, aos quais são adicionados em peque- nas quantidades. O objetivo deste trabalho foi o de investigar as propriedades reológicas de pectinas de alto grau de metoxilação produzidas no Brasil. $\mathrm{O}$ processo de gelificação em presença de sacarose foi estudado através da variação dos parâmetros viscoelásticos na vizinhança de transição de fase sol-gel. Os resultados obtidos permitiram inferir sobre a hierarquia das forças de ligação envolvidas na formação do gel.

\section{Experimental}

Duas amostras de pectina cítrica, denominadas pectinas A e B, fornecidas pela Braspectina (Limeira, SP), com alto teor em grupos metoxílicos e com diferentes graus de metoxilação foram utilizadas neste trabalho. Foram purificadas por meio de dissolução em água destilada e deionizada e filtração, sob pressão de $10^{5} \mathrm{~Pa}$ de nitrogênio comprimido, através de membranas Millipore de $3 \mathrm{e}$ $1,2 \mu \mathrm{m}$ de diâmetro de poro. Após a filtração, a forma predominantemente sódica da pectina foi obtida por meio de troca iônica em solução de $\mathrm{NaCl}$ (levando-se em conta a fração molar pectina/grupos carboxílicos de 1:0,25 para a pectina $\mathrm{A}$ e de 1:0,35 para a pectina B). O polímero foi recuperado pela precipitação em álcool etílico, e seco sob pressão reduzida a temperatura ambiente.

A razão galacturonato de metila/ácido galacturônico ou grau de metoxilação, GM, das amostras A e B foi determinada após hidrólise ácida do polímero, e os monossacarídeos resultantes analisados por cromatografia líquida de alta eficiência, HPLC $^{[15]}$.

Os teores de açúcares neutros das amostras de pectina foram obtidos mediante hidrólise ácida, seguida de redução e posterior acetilação. A análise dos açúcares resultantes foi realizada por cromatografia gasosa, GLC ${ }^{[16]}$, utilizando-se a arabinose como padrão interno. A hidrólise total das pectinas foi realizada em solução aquosa $2 \mathrm{M}$ de ácido trifluoroacético, a $100^{\circ} \mathrm{C}$, durante $3 \mathrm{~h}$. O produto da hidrólise foi neutralizado com carbonato de bário. $\mathrm{O}$ produto de hidrólise era levado à secura, sob pressão reduzida, a $45^{\circ} \mathrm{C}$. $200 \mu \mathrm{L}$ de uma solução redutora de $2,5 \mathrm{mg} / \mathrm{mL}$ de $\mathrm{NaBH}_{4}$ em $0,5 \mathrm{M}$ de $\mathrm{NH}_{4} \mathrm{OH}$ eram adicionados ao produto de hidrólise que, após homogeneização era deixado em repouso por $1 \mathrm{~h}$ a temperatura ambiente. Após esse período, 
as soluções eram neutralizadas com ácido acético e os produtos de redução levados à secura, sob pressão reduzida, a $45^{\circ} \mathrm{C} \cdot 0,2 \mathrm{~mL}$ de uma mistura anidrido acético: 4-(dimetilamina)-piridina, na proporção 10:1, foi adicionado sobre o produto de redução e homogeneizado. Esta acetilação foi realizada a $100^{\circ} \mathrm{C}$ por um período de $1 \mathrm{~h}$. Após repouso por $12 \mathrm{~h}$, os alditóis acetilados foram extraídos com $\mathrm{HCCl}_{3}$.

Dois tipos de reômetros foram utilizados neste trabalho para a caracterização reológica das duas amostras; o reômetro Contraves Low-shear 40, LS-40, e o reômetro Haake RheoStress, RS-100. O LS-40 permite a determinação de medidas de viscosidade e de propriedades viscoelásticas dentro de um regime de baixo cisalhamento. O RheoStress RS-100 é um reômetro rotacional de tensão controlada e que também segue o princípio de Couette em regime de cisalhamento alto. As soluções eram colocadas no sistema de medida e permaneciam em repouso por $10 \mathrm{~min}$. antes da realização dos testes. Em todas as medidas realizadas sob temperatura superior a $25^{\circ} \mathrm{C}$, foi utilizado um sistema que mantinha a amostra encapsulada, evitando a evaporação do solvente.

Para a determinação das viscosidades intrínsecas das amostras, soluções-mãe das amostras de pectina a 2,0 g/L foram preparadas em $0,1 \mathrm{M}$ de $\mathrm{NaCl}$, a $\mathrm{pH} 3,0$ e a $\mathrm{pH} 7,0$ e filtradas em membranas Millipore de 0,45 $\mu \mathrm{m}$ de diâmetro de poro. Soluções diluídas em $0,1 \mathrm{M}$ de $\mathrm{NaCl}$, a pH 3,0 e a $\mathrm{pH} 7$, foram analisadas sob cisalhamento contínuo em reômetro LS-40, equipado com geometria de cilindros coaxiais (MS-DIN 412), na faixa de taxa de cisalhamento, $\dot{\gamma}$, correspondente ao platô newtoniano. As concentrações das soluções foram escolhidas de modo a fornecer viscosidades relativas entre 1,2 a 2,0, e garantir a extrapolação linear à concentração zero ${ }^{[17]}$. As equações de Huggins (Equação 1) e de Kraemer (Equação 2) foram utilizadas.

$$
\begin{aligned}
& \left(\eta_{\mathrm{sp}}\right) / \mathrm{C}=[\eta]+\mathrm{k}_{\mathrm{H}}[\eta]^{2} \mathrm{C} \\
& \left(\ln \eta_{\mathrm{red}}\right) / \mathrm{C}=[\eta]-\mathrm{k}_{\mathrm{K}}[\eta]^{2} \mathrm{C}
\end{aligned}
$$

onde $\mathrm{k}_{\mathrm{H}}$ e $\mathrm{k}_{\mathrm{K}}$ são os coeficientes de Huggins e de Kraemer, respectivamente, e $\mathrm{C}$ é a concentração da solução, dada em g/dL.

A transição de fase sol-gel foi monitorada medindo-se os módulos de armazenamento, G', e de perda, G”, a uma freqüência fixa de $0,464 \mathrm{~Hz}$ como uma função do tempo, no RheoStress RS-100, equipado com um sistema cone-placa $\left(4^{\circ} / 35 \mathrm{~mm}\right)$.

Para o estudo da cinética de gelificação, a quantidade necessária de pectina era dispersa em água destilada e deionizada, aquecida a $95^{\circ} \mathrm{C}$ durante 5 minutos. Sob aquecimento e agitação constantes, a quantidade necessária de sacarose era adicionada em três porções e o sistema pectinasacarose, a $\mathrm{pH} 3,0$, era mantido a $95^{\circ} \mathrm{C}$ por um período de 15 minutos. A água perdida por evaporação era reposta e a amostra transferida para $o$ sistema de medida do instrumento na temperatura da análise. O tempo decorrido desde o início do processo de aquecimento até o início da análise era de 18 minutos.

\section{Resultados e Discussão}

Os resultados de análise mostraram que a pectina A apresentou grau de metoxilação $\mathrm{GM}=64 \%$, enquanto que na pectina $\mathrm{B}, \mathrm{GM}=57 \%$.

$\mathrm{Na}$ Tabela 1, são apresentados os teores de açúcares neutros e sua composição nas amostras das pectinas purificadas e analisadas por GLC. A pectina $\mathrm{A}$ contém um teor de açúcares neutros maior do que a pectina B (Tabela 1). Durante a extração da pectina, o processo mais utilizado produz pectina com grau de esterificação mais alto, geralmente entre 70 e $80 \%$. Já as pectinas com menor grau de metoxilação são produzidas por desesterificação controlada de pectinas com alto grau de metoxilação, em meio ácido, básico ou enzimaticamente, sendo a desesterificação ácida a mais usada ${ }^{[11]}$. Portanto, a diferença nos teores e

Tabela 1. Teor de açúcares neutros e sua composição nas amostras de pectina A e B.

\begin{tabular}{lcc}
\hline \multicolumn{1}{c}{ Açúcar neutro } & Pectina A & Pectina B \\
\hline Ramnose & 1,89 & 36,70 \\
Fucose & 25,95 & - \\
Ribose & 23,20 & - \\
Arabinose & 6,06 & 7,45 \\
Manose & 16,76 & 36,04 \\
Galactose & 26,14 & 19,81 \\
Total de açúcares neutros & 10,56 & 7,52 \\
(\% m/m) contidos na pectina. & & \\
\hline
\end{tabular}

Nota: A composição está em \% m/m, em relação ao total de açucares neutros 
composição dos açúcares neutros das amostras de pectina estudadas pode ser atribuída a diferenças nas fontes da matéria-prima.

Analisando a composição dos açúcares neutros na Tabela 1, verifica-se que o teor de L-ramnose aumenta na amostra $\mathrm{B}$, em relação à amostra $\mathrm{A}$. Por outro lado, a fucose e a ribose não são detectados na amostra B. Ainda, o teor de manose aumenta e o de galactose diminui na amostra B, em relação à amostra A. Isto pode ser explicado pelo fato de a ligação glicosídica $(1 \rightarrow 2)$ entre o $\mathrm{C}-1$ do ácido galacturônico e o C-2 da ramnose ser uma ligação resistente à hidrólise ácida ${ }^{[18,19]}$, enquanto que as ligações dos outros açúcares neutros à ramnose são lábeis em meio ácido.

A Tabela 2 apresenta valores de viscosidade intrínseca, [ๆ]. Pode-se verificar que esses valores a pH 7,0 são maiores do que a $\mathrm{pH} 3,0$ para ambas as amostras. $\mathrm{O}$ valor mais baixo de [ $\eta]$ a $\mathrm{pH} 3,0$ pode ser atribuído à contração da cadeia de pectina, um polieletrólito, devido à supressão de repulsões eletrostáticas intermoleculares e/ou a um aumento na interação segmentar intramolecular. Comparando os valores de $[\eta]$ de ambas as pectinas a $\mathrm{pH} 7,0$, a pectina $\mathrm{B}$ possui um valor menor, o que era inesperado, pois a pectina B possui um GM menor. A pH 3,0, os resultados estão concordantes com o esperado, pois em pectinas de alto grau de metoxilação a viscosidade das soluções geralmente aumenta com o grau de metoxilação crescente.

Testes preliminares mostraram que a concentração mínima de pectina que resultava em gel, em espaço de tempo relativamente curto, era de aproximadamente $3 \mathrm{~g} / \mathrm{L}$. O pH necessário para a formação desses géis foi testado na faixa de 2,0 a 3,5 , sendo o pH 3,0 escolhido. A concentração de sacarose escolhida foi de $60 \%$ (em peso), após avaliações na faixa de 55 a $80 \%$ (em peso). Para estudar o sistema pectina/sacarose na transição de fase sol-gel foram escolhidas as concentrações de pectina na faixa de 3 a $10 \mathrm{~g} / \mathrm{L}$.

Tabela 2. Valores de $[\eta]$ e $\mathrm{k}_{\mathrm{H}}$ para as amostras de pectinas purificadas, a $25^{\circ} \mathrm{C}$, em $0,1 \mathrm{M} \mathrm{NaCl}$, e a pH 3,0 e 7,0 .

\begin{tabular}{lcccccc}
\hline & \multicolumn{3}{c}{ Pectina A } & \multicolumn{3}{c}{ Pectina B } \\
\cline { 2 - 7 } Sistema & $\begin{array}{c}{[\eta]} \\
(\mathrm{d} 1 / \mathrm{g})\end{array}$ & $\mathrm{k}_{\mathrm{H}}$ & $\mathrm{r}^{2}$ & $\begin{array}{c}{[\eta]} \\
(\mathrm{d} 1 / \mathrm{g})\end{array}$ & $\mathrm{k}_{\mathrm{H}}$ & $\mathrm{r}^{2}$ \\
\cline { 2 - 7 } & 3,36 & 0,60 & 0,998 & 3,24 & 0,70 & 0,997 \\
$\begin{array}{l}0,1 \mathrm{M} \mathrm{NaCl} \\
\mathrm{pH} \mathrm{3,0}\end{array}$ & & & & & & \\
$\begin{array}{l}0,1 \mathrm{M} \mathrm{NaCl} \\
\mathrm{pH} \mathrm{7,0}\end{array}$ & 3,68 & 0,21 & 0,984 & 3,56 & 0,30 & 0,989 \\
\hline
\end{tabular}

Na Figura 2 são apresentadas, como exemplos, as curvas que representam a evolução de G' e G” (a uma freqüência constante de $0,464 \mathrm{~Hz}$ ) em função do tempo de gelificação e da concentração da pectina A (na faixa de concentração de 3 a $10 \mathrm{~g} / \mathrm{L}$ ) em presença de $60 \%$ de sacarose, a $25^{\circ} \mathrm{C}$. Para ambos os polímeros, no início do processo de gelificação, o módulo de perda é maior que o módulo de armazenamento, G" > G', caracterizando um comportamento viscoso do sistema. Com a evolução do tempo, G' e G' aumentam, como conseqüência do aumento do número de zonas junção. $\mathrm{O}$ G' aumenta mais acentuadamente do que o G', e após a interseção das duas curvas, G' passa a exceder G'.

O critério utilizado neste trabalho para determinar o ponto gel foi o tempo necessário para que G' e G' se igualassem, em uma dada freqüência ${ }^{[20,21]}$. $\mathrm{Na}$ verdade, a igualdade de G' e G" não deve ser considerada como uma propriedade universal do ponto gel, pois o tempo necessário para que a interseção de G' com G” ocorra pode ser muito próximo, mas não é idêntico ao tempo necessário para a transição de fase sol-gel. No entanto, esse critério é simples e vem sendo utilizado por muitos autores. Deve-se, porém, levar em conta que o momento de interseção de G' com G" depende da freqüência do experimento dinâmico e, portanto, não deve ser usado como um critério absoluto para a determinação do ponto gel ${ }^{[20,21]}$.

Após a interseção de G' com G', G'continua tendo uma grande variação crescente, enquanto que o G” também aumenta, mas menos acentuadamente. Este aumento rápido de G' resulta da formação rápida de zonas de junção entre cadeias de pectina que formam a rede do gel.

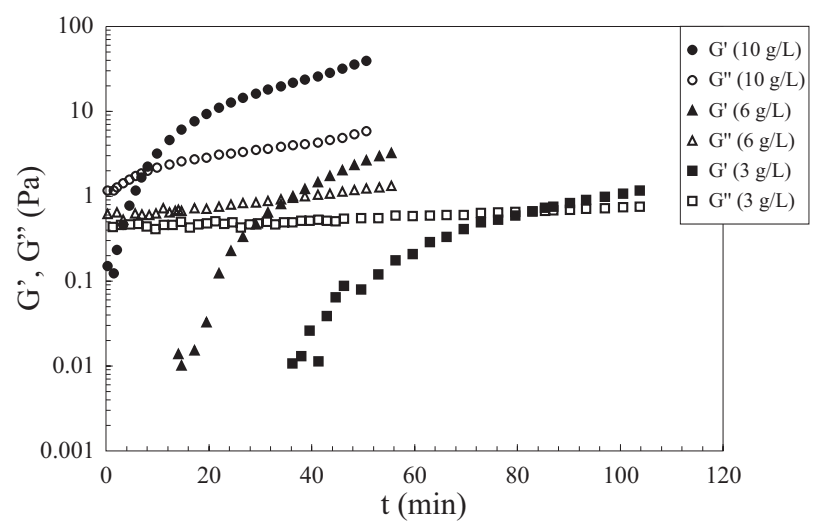

Figura 2. Cinéticas de gelificação para a pectina $\mathrm{A}$ em presença de $60 \%$ de sacarose na vizinhança de transição de fase sol-gel em função da concentração de polímero, a $25^{\circ} \mathrm{C}$, e a $0,464 \mathrm{~Hz}$. 
Ainda na Figura 2, as curvas que representam G' como uma função do tempo, para diferentes concentrações de pectina $\mathrm{A}$, mostram que com o aumento da concentração, a variação de $G$ ' é mais acentuada antes da transição de fase sol-gel. Entretanto, a concentrações mais baixas, $G^{\prime}$ aumenta mais lentamente seguido por um aumento relativamente mais acentuado. Além disso, o tempo necessário para o cruzamento de G' e G' aumenta com o decréscimo da concentração. Comportamento similar foi encontrado para outros biopolímeros ${ }^{[22,23]}$ como por exemplo o sistema pectina de baixo grau de metoxilação/cálcio ${ }^{[24]}$.

A Figura 3 mostra que o tempo de transição de fase sol-gel, $t_{\mathrm{g}}$, diminui com o aumento de concentração de pectina, o que está de acordo com dados reportados na literatura ${ }^{[18]}$. Porém, para as pectinas $\mathrm{A}$ e $\mathrm{B}$, os valores absolutos são diferentes. $\mathrm{O}$ perfil da curva $t_{g}(\mathrm{~min})$ versus $C(\mathrm{~g} / \mathrm{L})$ confirma que o grau de metoxilação é o fator intrínseco mais importante para a gelificação de amostras de HMP, controlando a taxa de formação das zonas de junção da rede durante o processo de gelificação ${ }^{[8,25]}$. A transição de fase sol-gel para a pectina A que apresenta o maior grau de metoxilação é sempre mais rápida, para uma dada concentração, do que para a pectina $\mathrm{B}$, em todas as concentrações estudadas. Geralmente, para as HMP, o tempo de gelificação é inversamente proporcional ao grau de esterificação ${ }^{[26]}$.

O valor de G' no ponto gel é plotado como uma função da concentração para as pectinas A e B na Figura 4. A pectina A, além de necessitar de

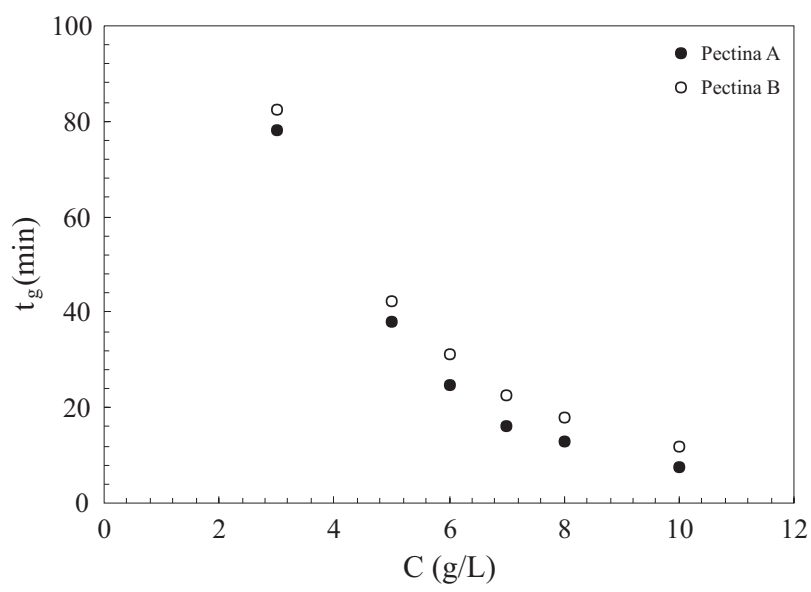

Figura 3. Variação do tempo de transição de fase sol-gel para as amostras de pectina A e B em presença de $60 \%$ de sacarose, em função da concentração de polímero, a $25^{\circ} \mathrm{C}$ e a $0,464 \mathrm{~Hz}$.

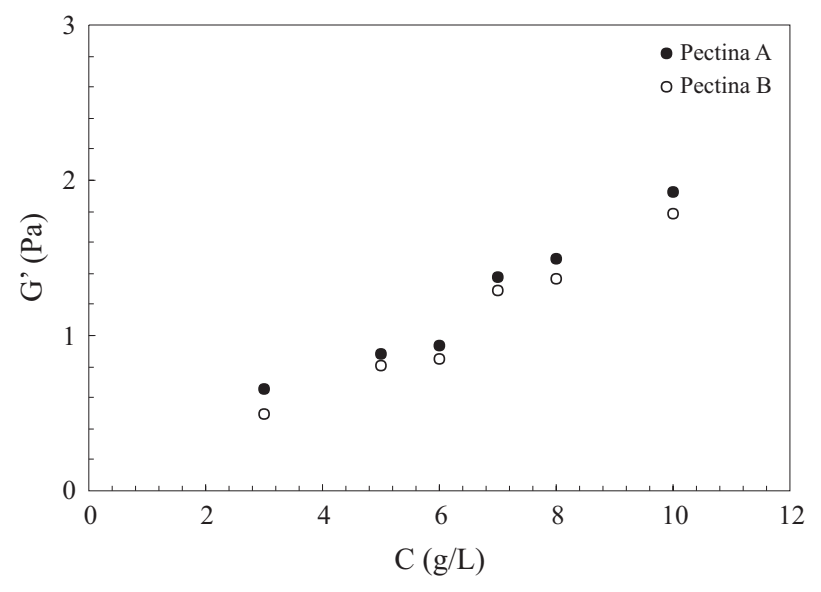

Figura 4. Variação do módulo de armazenamento, no ponto de interseção de G' com G', em função da concentração, para as amostras de pectina $\mathrm{A}$ e $\mathrm{B}$.

menor tempo para a transição, fornece valores de G' maiores do que aqueles da pectina $\mathrm{B}$, em toda a faixa de concentração estudada. Provavelmente, o gel de pectina A possui um número maior de zonas de junção.

A investigação do processo de gelificação em sistemas HMP-sacarose tem mostrado que o tempo de gelificação apresenta uma dependência complexa com a temperatura ${ }^{[27,28]}$. As interações hidrofóbicas, eletrostáticas e ligações de hidrogênio contribuem para a formação e estabilização da rede do gel e essas interações são afetadas pela temperatura.

No presente trabalho, a formação do gel foi investigada em função da temperatura, medindose os valores de G' e de G" a uma freqüência fixa de 0,464 Hz, como uma função do tempo, para ambas as amostras de pectina, na concentração de 7 g/L. Como exemplo, a Figura 5 mostra os resultados obtidos para a pectina A. Tanto para esta pectina como para a pectina $\mathrm{B}, \mathrm{G}$ ' e G' aumentam em função do tempo, para todas as temperaturas estudadas. Pode-se observar que a taxa de variação dos módulos e o tempo de gelificação, $t_{\mathrm{g}}$, dependem da temperatura na qual o experimento foi realizado. A $15^{\circ} \mathrm{C}$, a transição de fase sol-gel é mais lenta. A $25^{\circ} \mathrm{C}$, o valor de $\mathrm{G}^{\prime}$ no ponto gel é maior do que aqueles obtidos sob as demais temperaturas.

Para ilustrar a influência da temperatura no processo de gelificação o gráfico da Figura 6 foi elaborado. Esta figura mostra a dependência do tempo de gelificação em função da temperatura, para as pectinas A e B. Nas faixas de temperatura de 15 a $25^{\circ} \mathrm{C}$ e de 


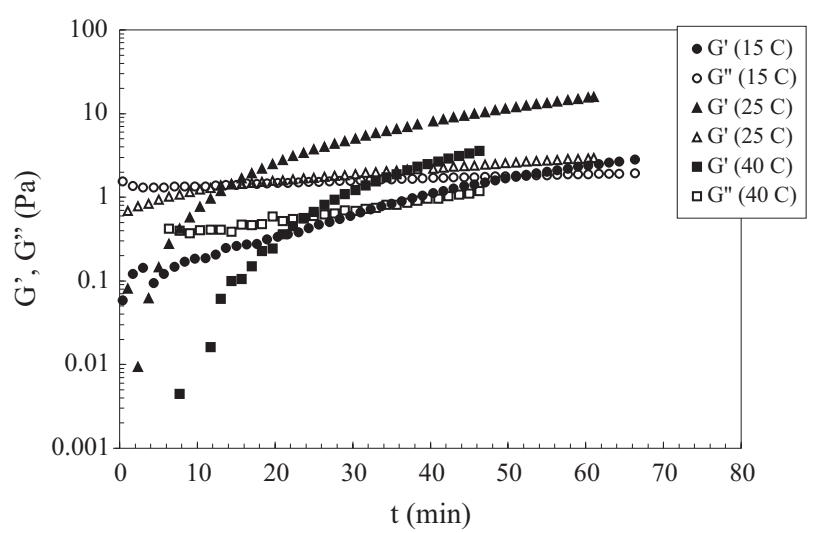

Figura 5. Cinética de gelificação para a pectina $A$ a $7 \mathrm{~g} / \mathrm{L}$, em presença de $60 \%$ de sacarose, na vizinhança da transição de fase solgel em função da temperatura, a $0,464 \mathrm{~Hz}$.

15 a $35^{\circ} \mathrm{C}$ para as pectinas $\mathrm{A}$ e $\mathrm{B}$, respectivamente, o tempo necessário para a transição de fase sol-gel decresce. Este resultado pode ser atribuído à contribuição crescente das interações hidrofóbicas à formação da rede tridimensional, com o aumento da temperatura. A pectina A sofre uma influência maior da temperatura por possuir maior grau de metoxilação.

Os resultados das Figuras 5 e 6 evidenciam que há uma temperatura ótima para o processo cinético de gelificação, a qual varia com o grau de metoxilação. Para a pectina $\mathrm{A}$ a temperatura ótima de gelificação fica em torno de $25^{\circ} \mathrm{C}$ e, para a pectina $\mathrm{B}$, o tempo de transição de fase sol-gel atinge a estabilidade a partir de $28^{\circ} \mathrm{C}$. A nível molecular, a temperatura ótima corresponde a um máximo da cooperação das interações hidrofóbicas e ligações de hidrogênio. Analisando a variação do tempo de gelificação com a temperatura, pode ser notado que,

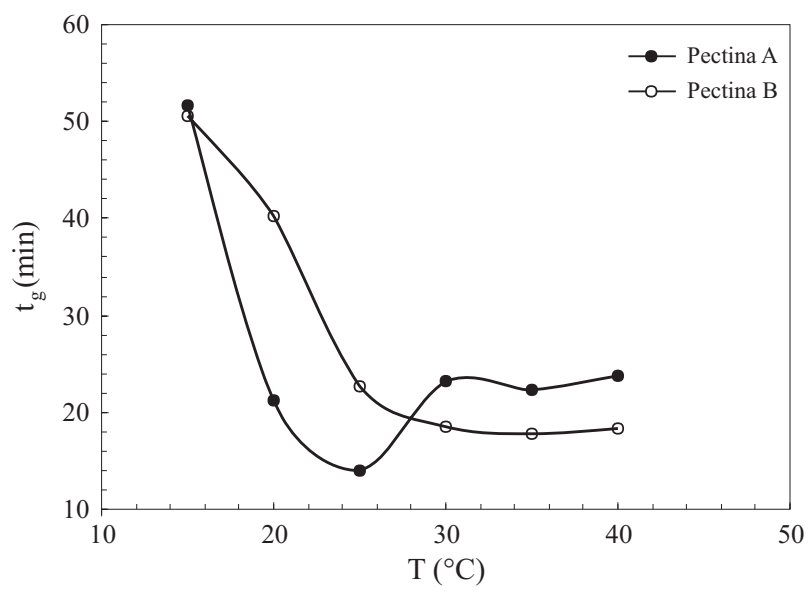

Figura 6. Variação do tempo de transição de fase sol-gel para as amostras de pectina A e B, a 7,0 g/L e $60 \%$ de sacarose, em função da temperatura, a $0,464 \mathrm{~Hz}$. entre 15 e $25^{\circ} \mathrm{C}$, ocorre um decréscimo acentuado no tempo de gelificação e que, na faixa de 30 a $40^{\circ} \mathrm{C}$, o tempo de gelificação permanece praticamente constante. Entretanto, para a pectina A, na faixa de temperatura analisada, um comportamento interessante é observado. A partir de aproximadamente $25^{\circ} \mathrm{C}$, o tempo de gelificação volta a aumentar e passa a exceder os valores obtidos para a pectina $\mathrm{B}$ no mesmo intervalo de temperatura.

Com base nos resultados experimentais obtidos no presente trabalho, ligações de hidrogênio e interações hidrofóbicas contribuem para formação da rede de HMP-sacarose. Essas ligações secundárias sofrem diferentemente o efeito da temperatura; enquanto que as ligações de hidrogênio são estabilizadas pelo abaixamento de temperatura, as ligações hidrofóbicas são formadas a temperaturas mais elevadas ${ }^{[13,14,27]}$.

$\mathrm{O}$ método utilizado neste trabalho visava a obtenção de géis bem estruturados. Para tal, foi planejado o aquecimento inicial das soluções, para favorecer a formação de ligações hidrofóbicas e que levam a uma conformação macromolecular compacta.

Com o resfriamento, um número maior de ligações de hidrogênio serão formadas, tendo-se em vista a proximidade entre os sítios ativos.

Desta forma, a temperaturas inferiores a $30^{\circ} \mathrm{C}$, a rede tridimensional é formada por uma maior cooperação entre ligações de hidrogênio e interações hidrofóbicas, e que necessitam de um período de tempo maior para a sua formação e que levam a estruturas mais fortes ${ }^{[14]}$. Por outro lado, com o aumento da temperatura, o ponto gel é caracterizado por rede tridimensional mais fraca, devido à menor contribuição de ligações de hidrogênio, e que se forma mais rapidamente devido à contribuição predominante de ligações hidrofóbicas ${ }^{[13,14]}$.

\section{Conclusões}

A redução nos valores das viscosidades intrínsecas, observados a $\mathrm{pH} 3,0$, indicam uma tendência à contração das cadeias de pectina em solução, através de ligações de hidrogênio e interações hidrofóbicas intramoleculares.

O grau de metoxilação mostrou ser o fator intrínseco mais importante para a gelificação de pectinas, uma vez que a transição de fase sol-gel 
para pectina $\mathrm{A}$ foi sempre mais rápida, pois em condições de baixo pH seqüências de cadeias esterificadas são capazes de formar associações estáveis a temperaturas mais altas e que são estabilizadas com o decréscimo da temperatura.

No ponto da transição de fase sol-gel, a pectina A apresentou valores de $G$ ' iguais a $G$ " sempre maiores do que aqueles da pectina $\mathrm{B}$, possivelmente por formar um número maior de zonas de junção.

O sistema pectina/sacarose mostrou ser bastante complexo durante o processo de gelificação em função da temperatura, com predominância de interações do tipo ligação de hidrogênio a baixas temperaturas e interações hidrofóbicas a temperaturas mais altas. Portanto, dependendo da temperatura, as zonas de junção são formadas e estabilizadas por contribuições diferentes de interações hidrofóbicas e ligações de hidrogênio, o que afeta a estrutura da rede e o comportamento viscoelástico no ponto de transição de fase sol-gel.

Em tempo relativamente curto, a temperatura ótima de gelificação pôde ser determinada para as amostras de pectina.

\section{Agradecimentos}

Os autores agradecem à Braspectina S.A. pelo fornecimento das amostras, ao CENPES/PETROBRAS pela utilização do Reômetro RS100 e à CAPES e ao $\mathrm{CNPq}$ pelo apoio financeiro.

\section{Referencias Bibliográficas}

1 - Aspinall, G.O. - "Pectins, plants gums, and other plant polysaccharides". in: The Carbohydrates Chemistry and Biochemistry. V. Pigman \& D Horton (ed.).. New York: Academic Press. v.2b, p. 515 (1970).

2 - Hwang, J.; Pyun, Y. R. \& Kokini, J.L. - Food Hydrocoll., 7, p. 39 (1993).

3 - Ptitchkina, N.M.; Danilova, I.A.; Doxastakis, G.; Kasapis, S. \& Morris, E.R. - Carbohydr. Polym., 23, p. 265 (1994).

4 - Axelos, M.A.V.; Thibault, J.F \& Lefèbvre, J. - Int. J. Biol. Macromol., 11, p. 186 (1989).

5 - Stoddart, R.W.; Barrett, A.J. \& Northcote, D.H. Biochem. J., 102, p. 194 (1967).

6 - Rombouts, F.M. \& Pilnik, W. - Process Biochem., 13, p. 9 (1978).
7 - Powell, D.A.; Morris, E.R.; Gidley, M.J. \& Rees, D.A. J. Mol. Biol., 155, p. 517 (1982).

8 - Hwang, J. \& Kokini, J.L. - Carbohydr. Polym., 19, p. 41 (1992).

9 - Grasdalen, H.; Bakoy, O.E. and Larsen, B. - Carbohydr. Res., 184, p. 183 (1988).

10 - Leitão, M.C.A.; Alcatrão Silva, M.L.; Januário, M.I.N. \& Azinheira, H.G. - Carbohydr. Polym., 26, p. 165 (1995).

11 - Caderno de Informações técnicas - Braspectina S.A (1990).

12 - Fishman, M.L.; Pfeiffer, P.T.; Barford, R.A. and Doner, L.W. - J. Agric. F. Chem., 32, p. 372 (1984).

13 - Chronakis, I.S.; Kasapis, S. and Abeysekera, R. - Food Hydrocoll., 11, p. 271 (1997).

14 - Al-Ruqaie, I.M.; Kasapis, S. and Abeysekera, R. Carbohydr. Polym., 34, p. 309 (1997)

16 - Albershein, P.; Nevins, D.J., English, P.D. \& Karr, A. Carbohydr. Res., 5, p. 340 (1967).

17 - Morris, E.R. \& Ross-Murphy, S.B. "Chain flexibility of polysaccharides and glycoproteins from viscosity measurements". in: Techniques in Carbohydr. Metabolism, B310, D.H. Northcode (ed.), Elsevier/ North Holland Scientific Publishers Ltd., Amsterdam (1981).

18 - Bemiller, J.N. - Adv. Carbohydr. Chem., 22, p. 25 (1967).

19 - Thibault, J. F.; Renard, C. M. G. C.; Axelos, M. A. V.; Roger, P. \& Crépeau, M. J. - Carbohydr. Research, 238, p. 271 (1993).

20 - Stading, M. \& Hermansson, A.M. - Food Hydrocoll., 4, p. 121 (1990).

21 - Stading, M. \& Hermansson, A.M. - Carbohydr. Polym., 22, p. 49 (1993).

22 - Tang, J.; Tung, M.A. \& Zeng, Y. - Carbohydr. Polymers, 29 (1), p. 11 (1996)

23 - Michel, A.S.; Mestdagh, M.M., \& Axelos, M.A.V. - I. J. Biol. Macromol., 21, p. 195 (1997).

24 - Ross-Murphy, S.B. - Rheologica Acta, 30, p. 401 (1991).

25 - Powell, D.A.; Morris, E.R.; Gidley, M.J. \& Rees, D.A. - J. Mol. Biological, 155, p. 517 (1982)

26 - Smit, C.J.B. \& Bryant, E.F. - J. Food Sci., 33, p. 262 (1968).

27 - Rao, M.A.; Van Buren, J.P. and Cooley, H.J. - J. Food Sci.,58, p. 173 (1993).

28 - Rolin, C. - "Pectin". in: Industrial Gums.. Whistler, R.L and BeMiller, J.N. (ed). Academic Press. London. p. 257 (1993).

29 - Hourdet, D. \& Muller, G. - Carbohydr. Polym., 16, p. 409 (1991).

Recebido: 18/01/99

Aprovado: 27/09/99 